\title{
A CONSTITUIÇÃO E AS POLÍTICAS PÚBLICAS EM PORTUGAL
}

\author{
Maria de Lurdes Rodrigues \\ Instituto Universitário de Lisboa (ISCTE-IUL) e Centro de Investigação e Estudos de Sociologia \\ (CIES-IUL), Lisboa, Portugal \\ Pedro Adão e Silva \\ Instituto Universitário de Lisboa (ISCTE-IUL) e Centro de Investigação e Estudos de Sociologia \\ (CIES-IUL), Lisboa, Portugal
}

\begin{abstract}
Resumo As políticas públicas desenvolvidas ao longo dos últimos 30 anos em Portugal encontram os seus fundamentos na Constituição aprovada em 1976 e nas suas sucessivas revisões. A inscrição constitucional da obrigação do estado de promover políticas públicas para assegurar a construção do estado social, garantindo a todos os cidadãos a protecção social, a saúde e a educação, resultou de compromissos político-partidários que foram decisivos para a construção dos serviços públicos universais e gratuitos que hoje conhecemos.
\end{abstract}

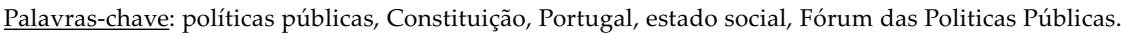

Abstract The legal foundation for the public policies developed and pursued in Portugal over the last 30 years is the 1976 Constitution and its successive revisions. The inclusion in the Constitution of an obligation on the part of the state to promote and organise public policies designed to construct a welfare state, guaranteeing social protection, healthcare and education for all, was the result of party political commitments that were decisive elements in the creation and consolidation of the free and universal public services we know today.

Keywords: public policies, Constitution, Portugal, welfare state, Public Policy Forum.

Résumé Les politiques publiques mises en œuvre au long des 30 dernières années au Portugal sont fondées sur la Constitution adoptée en 1976 et ses révisions successives. L'inscription constitutionnelle de l'obligation de l'État de promouvoir des politiques publiques pour assurer la construction de l'État social, en garantissant à tous les citoyens la protection, la santé et l'éducation, est le fruit d'engagements politiques qui furent décisifs pour la construction des services publics universels et gratuits que nous connaissons aujourd'hui.

Mots-clés: politiques publiques, Constitution, Portugal, État social, Forum des Politiques Publiques.

Resumen Las políticas públicas desarrolladas a lo largo de los últimos 30 años en Portugal encuentran sus fundamentos en la Constitución aprobada en 1976 y en sus revisiones sucesivas. La inscripción constitucional de la obligación del estado de promover políticas públicas para asegurar la construcción del estado social, garantizando a todos los ciudadanos la protección social, la salud y la educación, resultó de compromisos político-partidarios que fueron decisivos para la construcción de los servicios públicos universales y gratuitos que hoy conocemos.

Palabras-clave: políticas públicas, constitución, Portugal, estado social, Foro de las Políticas Públicas.

As políticas públicas desenvolvidas ao longo dos últimos 30 anos encontram os seus fundamentos na Constituição aprovada em 1976 e nas suas sucessivas revisões. O quadro constitucional de definição e de concretização de políticas públicas, em setores como a saúde, a proteção social, a educação, o território, bem 
como de promoção da igualdade e da justiça, permitiu transformar e modernizar o país. ${ }^{1}$

O texto constitucional está organizado em quatro partes. É no final da parte I, "Direitos e deveres fundamentais", do artigo 63. ao $79 .$. , que se encontram os princípios constitucionais que consagram a obrigação do estado de promover políticas públicas para assegurar e garantir a construção do estado social e o acesso de todos, em condições de igualdade, isto é, independentemente da sua condição económica ou social, de raça ou de género, a serviços de proteção social (artigo 63. ${ }^{\circ}$ ), de saúde (artigo $64 .^{\circ}$ ) e de educação ( $\operatorname{artigos} 74 .^{\circ}$ a $76 .^{\circ}$ ), consagrando ainda deveres do estado no campo da habitação e do ordenamento do território (artigos 65.. e 66..$^{\circ}$ ).

Os fundamentos constitucionais das políticas de justiça encontram-se mais dispersos. Por um lado, derivam da consagração dos direitos, liberdades e garantias que asseguram a inclusão de todos como cidadãos, sem exclusão (artigo 12. ${ }^{\circ}$, sobre a universalidade), e a igualdade formal perante a lei (artigo 13. ${ }^{\circ}$, sobre a igualdade), bem como a proteção da vida, liberdade, escolhas e propriedade dos indivíduos, impedindo a ingerência, o abuso e o arbítrio de poder do estado, isto é, impondo limites e condições aos atos do estado que possam restringir ou limitar os direitos cívicos, as liberdades e as garantias pessoais (artigos 27. a a 35..$^{\circ}$ ). É a ordem constitucional tuteladora da vida e da liberdade de cada cidadão. Por outro lado, encontram-se ainda na parte III do texto constitucional, onde se institui o modelo da organização política segundo os princípios da separação ou divisão de poderes (artigos 108. . a 119..$^{\circ}$ ), definindo-se aí a organização do poder judicial, isto é, dos tribunais, o estatuto dos juízes, do Ministério Público e do Tribunal Constitucional (artigos 202.. a 224..$^{\circ}$ ).

Para analisar a construção do estado de direito democrático e social e a trajetória das políticas públicas na democracia é necessário ter em conta, para além da Constituição, outros diplomas legais. No caso das políticas de justiça, é necessário considerar as grandes leis ordenadoras em que se declina o direito à liberdade (como, entre outras, $\mathrm{o}$ Código Penal e o Código de Processo Penal, a Lei de Menores e a Lei da Saúde Mental) e as leis que organizam o sistema de justiça. No caso das políticas sociais, é necessário ter em conta as leis de bases dos sistemas sociais (como a Lei de Bases do Sistema Nacional de Saúde, a Lei de Bases da Segurança Social, a Lei de Bases do Sistema Educativo e a

1 O dossiê apresentado neste número especial da revista Sociologia, Problemas e Práticas reúne alguns dos trabalhos do Fórum das Políticas Públicas 2016, dedicado à análise dos "Fundamentos Constitucionais das Políticas Públicas em Portugal", realizado na Assembleia de República, nos dias 24 e 31 de maio. O Fórum das Políticas Públicas é uma iniciativa de professores e investigadores de políticas públicas do ISCTE-IUL, que se realiza desde 2011 e que tem como objetivos gerais, por um lado, promover o debate de ideias, o conhecimento e a informação sobre políticas públicas em Portugal e, por outro, contribuir para a melhoria da qualidade da sua conceção, concretização, regulação e avaliação.. As intervenções e debates das anteriores edições do Fórum foram reunidos em livros: Políticas Públicas em Portugal (INCM, 2012), Políticas Públicas para a Reforma do Estado (Almedina, 2013) e Governar com a Troika. Políticas Públicas em Tempo de Austeridade (Almedina, 2015). Em 2016 assinalou-se a passagem de 40 anos da aprovação da Constituição no dia 2 de abril de 1976 e este foi o pretexto para, em colaboração com a Assembleia da República, analisar e debater os fundamentos constitucionais das políticas públicas em Portugal. Foi dado particular destaque aos fundamentos constitucionais e às trajetórias das políticas públicas em setores como o da saúde, da protecção social, da educação, do território, bem como das políticas públicas de promoção da igualdade e da justiça, envolvendo no debate peritos e especialistas em políticas públicas e protagonistas políticos. 
Lei de Bases da Política de Solos, de Ordenamento do Território e Urbanismo), e outros diplomas setoriais estruturantes, nos quais se materializam os princípios constitucionais de garantia da liberdade, da universalidade, da igualdade e da igualdade de oportunidades. Estes diplomas preveem diferentes graus de aproximação ou afastamento dos princípios constitucionais, bem como de abertura e de flexibilidade, no que respeita, por exemplo, à relação do estado com os promotores dos setores privado, cooperativo e social, assim como à relação entre a administração central e o poder local.

\section{As revisões da Constituição}

A Constituição da República Portuguesa aprovada em 1976 afirmou um regime de estado de direito assente nos princípios da separação de poderes e da igualdade de todos os cidadãos, sem exclusão, perante a lei. E simultaneamente, afirmou o caráter social e democrático do estado, introduzindo, ao nível político, económico e social, importantes ruturas com o regime anterior. No que respeita às políticas públicas ficaram, em 1976, constitucionalizados, não apenas os direitos sociais, como também as obrigações do estado na criação de sistemas públicos de educação e de saúde e na promoção de serviços universais e gratuitos, para garantir a igualdade de oportunidades.

Ao longo destes 40 anos, a Constituição foi revista sete vezes. Destas revisões, três incidiram sobre questões estruturais, implicando significativos processos de alteração do articulado constitucional (1982, 1989 e 1997); e quatro estiveram relacionadas com a adesão a tratados internacionais, implicando revisões cirúrgicas (1992, 2001, 2004 e 2005).

A revisão de 1982 teve como principal objetivo desmilitarizar o regime e reafirmar os princípios do estado de direito democrático. No texto legislativo de 1976, a qualificação da República Portuguesa como um estado de direito estava consagrada apenas no Preâmbulo, sem valor legal, e foi nesta revisão constitucionalizada no artigo 2. . . No mesmo sentido a expressão preambular "sociedade sem classes", foi substituída por "sociedade livre, justa e solidária".

Na parte da organização política, foi extinto o Conselho da Revolução, sendo substituído pelo Tribunal Constitucional com a função de fiscalizar a constitucionalidade das leis. Até então, a função de fiscalização da constitucionalidade era assegurada pelo Conselho da Revolução, habilitado por uma Comissão Constitucional. Foi também criado um novo órgão, o Conselho de Estado, para aconselhamento do presidente da República, cujos poderes discricionários de demissão do governo e de dissolução da Assembleia da República foram então limitados, sendo reforçado o parlamentarismo.Ainda no que respeita à organização política, a competência do ministro da Justiça para nomear os juízes passa para os conselhos superiores de governo do poder judicial, aprofundando-se o princípio da separação de poderes.

Na parte da organização económica, introduziram-se várias modificações no sentido de liberalizar o sistema económico, diminuindo a intervenção do estado e abrindo espaço à iniciativa privada, afirmando-se uma organização económica mista. Contudo, continuaram no texto constitucional as referências às nacionalizações e à reforma agrária. 
A revisão de 1989 teve como principal objetivo prosseguir o processo de liberalização da economia. Assim, aprofundaram-se as alterações na II parte relativa à organização económica, visando afirmar o primado da economia de mercado. Diminuiram os deveres do estado de planificação económica, foi revogado o princípio da irreversibilidade das nacionalizações, consagrando-se a possibilidade de reprivatizações reguladas por lei-quadro aprovada por maioria absoluta dos deputados. Do articulado relativo à política agrícola foi abandonada a referência à reforma agrária, passando a referir-se apenas o objetivo de eliminação do latifúndio e de ordenamento do minifúndio.

No que respeita aos deveres do estado na concretização dos direitos sociais apenas foi alterado o artigo 64. ${ }^{\circ}$, ficando estabelecido que o Serviço Nacional de Saúde seria "universal, geral e tendencialmente gratuito", "tendo em conta as condições económicas e sociais dos cidadãos". Esta formulação manteve-se até hoje.

Na parte da organização política foi introduzida a possibilidade de referendo e definidas as condições de realização.

Em 1997, a revisão da Constituição incidiu basicamente sobre a parte da organização política, tendo sido revisitada a distribuição dos poderes pelos diferentes órgãos. Foram aumentados os poderes legislativos exclusivos da Assembleia da República, foram alargadas as competências do Tribunal Constitucional, e instituída a possibilidade de candidaturas de independentes às eleições autárquicas. No que respeita à composição e eleição da Assembleia da República, foi aberta a possibilidade de o número de deputados poder variar entre 180 e 230, bem como a de criação de círculos uninominais nas eleições legislativas. Foram alargados os direitos políticos dos cidadãos: os emigrantes adquiriram direito de voto na eleição do presidente da República e os cidadãos estrangeiros europeus ganharam capacidade eleitoral. No mesmo sentido foi reconhecido direito de iniciativa legislativa aos cidadãos e alargado o regime de referendo, impondo-se constitucionalmente que a regionalização fosse submetida a referendo.

As quatro revisões cirúrgicas de 1992, 2001, 2004 e 2005 foram determinadas pela integração do país na União Europeia e pela necessidade de adaptação da Constituição a diferentes tratados. Em 1992, a revisão constitucional consistiu na adaptação ao Tratado de Maastricht, tendo ficado consagrada a possibilidade de voto, para as eleições europeias, de cidadãos europeus a viver em Portugal, e a adesão à União Económica e Monetária. Em 2001, a alteração da lei fundamental visou a adaptação às disposições do Tribunal Penal Internacional, sendo revistas as regras de extradição, de expulsão, de asilo e introduzidas restrições nos direitos de inviolabilidade do domicílio e da correspondência. Em 2004, a revisão constitucional visou aprofundar a integração da Constituição no campo jurídico-constitucional da União Europeia. Foi aperfeiçoada a compatibilidade do texto constitucional com as regras das relações internacionais e do direito internacional, nomeadamente com as normas da União Europeia e dos tratados europeus. No capítulo da organização política, foi dada mais autonomia às regiões autónomas e alargados os poderes das assembleias regionais. Foi ainda alargado o âmbito da limitação dos mandatos dos cargos políticos e eletivos. Em 2005, a revisão constitucional visou apenas permitir o referendo de tratados de construção europeia. 
Como vimos, as revisões e ajustamentos do texto constitucional incidiram quase exclusivamente sobre dois campos. Em primeiro lugar, as matérias de organização económica, com o objetivo de imprimir à economia uma orientação de mercado. Em segundo lugar, sobre a organização política, com o objetivo de, por um lado, conferir direitos políticos mais alargados aos cidadãos e, por outro, promover a redistribuição de poderes e competências, envolvendo o presidente da República, a Assembleia da República, o poder judicial, o poder local e as regiões autónomas, consolidando e aprofundando os princípios de separação de poderes, da independência e da autonomia.

Os deveres do estado na promoção de políticas sociais e de igualdade não sofreram alterações depois de 1989. Por que razão? Porque reuniam o apoio unânime de todas as forças partidárias? Ou, pelo contrário, permanecem ainda hoje significativas diferenças político-partidárias, mas não foi possível ao longo dos últimos 30 anos alterar a relação de forças e construir um outro compromisso?

\section{Os debates sobre a necessidade de rever a Constituição}

Um olhar sobre os debates públicos acerca da Constituição e da necessidade da sua revisão permite encontrar algumas respostas para estas questões. De facto os debates públicos permitem compreender o que distingue os diferentes partidos políticos, o que os afasta e o que os aproxima. Sobretudo depois de 2010, com os impactos da crise do sistema financeiro e da crise do euro na dívida pública, e com a adoção de políticas orçamentais restritivas de controlo do défice e da dívida, emergiram vários debates públicos sobre a necessidade de revisão da Constituição. Em 2010, foi desencadeado formalmente um processo de revisão constitucional promovido pela Assembleia da República por iniciativa do PSD. Em 2011, a propósito da passagem de 35 anos sobre a aprovação do texto constitucional, a Fundação Francisco Manuel dos Santos promoveu um debate que envolveu peritos de diferentes formações e sensibilidades políticas. Também entre 2011 e 2015, foimuito alargado o debate público em torno de decisões do Tribunal Constitucional acerca da constitucionalidade de medidas de política no contexto de aplicação do programa de ajustamento orçamental previsto no Memorando de Entendimento assinado pelo governo e a troika.

O debate na Assembleia da República em 2010

O processo de revisão constitucional aberto pela Assembleia da República, em 2010, por iniciativa do PSD, contou com a apresentação de propostas de todos os partidos políticos com assento parlamentar.

O projeto de revisão constitucional do PSD entregue na Assembleia continha duas propostas que geraram forte controvérsia. Em primeiro lugar, o abandono dos princípios da universalidade e gratuitidade dos serviços públicos de saúde e de educação e a constitucionalização do princípio do utilizador pagador: "nenhum português pode deixar de ter acesso à Saúde e à Educação por insuficiência de meios económicos". Expressões como "gratuito" e "tendencialmente gratuito" no 
acesso à educação e à saúde, seriam trocadas por "não podendo, em caso algum, o acesso ser recusado por insuficiência de meios económicos". O PSD foi buscar inspiração ao articulado respeitante às condições de acesso à justiça, onde estava já consagrada, desde 1976, a expressão "por insuficiência de meios económicos". A segunda proposta de alteração respeitava à substituição da "proibição de despedimentos sem justa causa" por "sendo proibidos os despedimentos sem razão legalmente atendível". Finalmente, o PSD propunha ainda que o texto constitucional fosse "expurgado da ideologia e da orientação programática e estatista".

OCDS-PP, nesta mesma linha, apresentou uma proposta para a supressão do preâmbulo da Constituição, sugerindo também alterações no vocabulário utilizado na lei fundamental, designadamente nas referências "eliminação dos latifúndios", "autogestão", "apropriação dos meios de produção", assim como "abolição do imperialismo", "desarmamento geral", "dissolução dos blocos político-militares". No que respeita aos fundamentos constitucionais das políticas públicas, o CDS propunha a inclusão da possibilidade de contratualização dos privados no Serviço Nacional de Saúde e a fixação de um limite para os impostos cobrados, no valor de $35 \%$ do PIB do país, bem como a obrigatoriedade da "discriminação dos encargos plurianuais suscetíveis de excederem a duração da legislatura em curso", visando assim proteger as gerações futuras. Na parte da organização política, o CDS propunha que a nomeação dos membros das entidades administrativas independentes passasse a fazer parte dos poderes do presidente da República, após audição prévia na Assembleia da República, incluindo a nomeação do presidente do Tribunal de Contas e do procurador-geral da República.

O PS respondeu à iniciativa do PSD com uma proposta de revisão constitucional minimalista, centrada nas questões de relacionamento do governo com a Assembleia da República e nos calendários eleitorais.

O Bloco de Esquerda, no seu projeto de revisão constitucional, pretendia "a afetação dos portos e aeroportos, e da rede elétrica nacional ao domínio público", tendo em vista a "defesa estratégica do país" (artigo 84.o ). No que respeita à organização política, o Bloco de Esquerda apresentou a proposta de descida da idade mínima de votar para 16 anos, e de atribuição de "capacidade eleitoral aos imigrantes legalmente residentes há mais de quatro anos, devendo poder votar e ser eleitos para a Assembleia da República, e Assembleias Legislativas das regiões autónomas".

$\mathrm{O} \mathrm{PCP}$, no seu projeto, apresentou propostas visando reforçar os direitos dos trabalhadores, com aumento do salário mínimo e redução do horário de trabalho, bem como melhorar o acesso aos serviços públicos de educação e de saúde. No capítulo dos direitos pretendia também eliminar as restrições ao direito à greve das forças de segurança e o reconhecimento "do direito de todos os cidadãos à água e ao saneamento básico". No campo da organização política, o PCP propunha a "eliminação da obrigatoriedade de referendo para a criação de regiões administrativas", e "das normas que permitem a sistemática transferência da soberania nacional para as instituições da União Europeia e que admitem a prevalência das normas emanadas da União Europeia sobre o Direito interno". Propunha ainda que os mandatos do procurador-geral da República, do provedor de Justiça e do presidente do Tribunal de Contas fossem fixados em seis anos, não renováveis. 
O Partido Ecologista / Os Verdes apresentou uma proposta visando a consagração constitucional da rejeição da energia nuclear, e ainda a clarificação do "objetivo de combate às alterações climáticas e de defesa da biodiversidade".

Os debates na sociedade civil entre 2010 e 2014

Entre 2010 e 2011, na sequência da crise económica e financeira, tanto o PSD como o CDS defenderam publicamente a necessidade de rever a Constituição com o propósito de inscrever a designada "regra de ouro", isto é, a fixação de um limite constitucional ao défice orçamental num valor abaixo dos 3\%. O PS recusou esta ideia e não foi apresentada qualquer proposta nesse sentido.

Num outro momento, em 2011, por ocasião dos 35 anos da Constituição, a Fundação Francisco Manuel dos Santos (FFMS) organizou um debate publicado em $e$-book, ${ }^{2}$ que envolveu cerca de 40 personalidades com diferentes formações e de diferentes quadrantes políticos. O debate resultou muito diferente dos habituais debates parlamentares. O estatuto das pessoas envolvidas no desafio de rever a Constituição (não apenas juristas, nem apenas deputados) e o contexto criado permitiram um debate sem os constrangimentos político-partidários habituais. Pode dizer-se que permitiram um debate intelectualmente mais livre, um debate marcado mais pela ética das convicções do que pela ética das responsabilidades.

Do conjunto do debate resultaram inúmeras propostas pragmáticas, mas não necessariamente realistas, sem que, em nenhum caso, no todo ou em parte, se colocasse em causa o regime instituído. Um dos organizadores do debate refere:

O país já está constituído em muitos aspetos: o poder local, a existência de regiões autónomas insulares, o núcleo essencial dos direitos, liberdades e garantias. Noutros pontos, está tudo em aberto: na regionalização, por exemplo. Outros pontos ainda estão relativamente em aberto ou, pelo menos, continuam a gerar dúvidas: o pendor mais ou menos presidencial do sistema de governo, o sistema eleitoral, a existência de uma jurisdição constitucional autónoma. [...] Contudo, não se defende que a Constituição deva ser mudada a fundo ou que deva ocorrer uma mudança de regime (António Araújo, "A Constituição como problema" , em FFMS (2011), A Constituição Revista).

As propostas apresentadas eram, em muitos casos, pontuais e marcadas por preocupações de agendamento de questões de conjuntura, sem referência a problemas constitucionais. Porém, em outros casos, propuseram-se soluções de aprofundamento técnico-político para problemas constitucionais concretos, pensadas independentemente da maior ou menor facilidade política da sua concretização.

No capítulo dos direitos, foram apresentadas propostas para a transferência para a esfera pública dos encargos e responsabilidades que resultam da garantia de direitos sociais atualmente assegurados pelas entidades empregadoras (artigos 59. e $^{2} 8$. $^{\circ}$ ). Na parte da organização económica, várias propostas íam no sentido da alteração de todo o articulado que constitucionaliza a orientação planificadora da

2 FFMS (2011), A Constituição Revista, Lisboa, FFMS [c05527e4-9fb8-4fe1-97b1-0264e172fe15.pdf]. 
economia para uma orientação liberal e de mercado, bem como no sentido da constitucionalização de limites e de mecanismos de controlo da dívida e da despesa pública e do aumento de receita por via fiscal.

No que respeita à organização política, é referida a necessidade de reforço do envolvimento do presidente da República e da Assembleia da República na indigitação e nomeação de dirigentes de cargos públicos ou entidades reguladoras; de alargamento dos poderes do presidente de dissolução do parlamento; de abandono dos círculos uninominais; e, ainda, de eliminação dos limites estabelecidos para a produção de efeitos dos resultados dos referendos e o alargamento dos direitos de participação política dos cidadãos e de organizações da sociedade civil.

As propostas apresentadas neste debate íam mais longe, sobretudo, no capítulo da organização dos tribunais (artigos 202.ำ a 220.ํ) e do Tribunal Constitucional (artigos 221. ${ }^{\circ}$ a $224 .{ }^{\circ}$ ), sobretudo no articulado que se considera ter maior impacto no sistema de justiça:

Em Portugal não existe uma "questão constitucional" sobre o significado do poder judicial e o estatuto dos juízes, como se verifica na leitura dos projetos de revisão constitucional, que não propõem alterações quanto às normas que definem e regulam a atividade dos tribunais, determinando a independência dos juízes e a obrigatoriedade das suas decisões para todas as autoridades públicas. Na realidade, os "graves problemas", que no dizer comum, a justiça enfrenta não se referem propriamente aos juízes e à sua atividade, mas ao "serviço de justiça" [...] problemas de atraso sistemático, de onerosidade, de ineficiência e de injustiça do próprio sistema legal e judicial. [...] Por essa razão nos processos de revisão constitucional "discute-se sobretudo a organização das jurisdições, com propostas relativas ao governo das magistraturas, visando a extinção do Conselho Superior dos Tribunais Administrativos e Fiscais e as mudanças na composição e no funcionamento do Conselho Superior de Magistratura (Vieira de Andrade, "Tribunal Constitucional e tribunais", em FFMS (2011), A Constituição Revista, pp. 115-116).

Neste sentido, neste debate foram apresentadas várias propostas. Em primeiro lugar, propostas de introdução de preceitos que concretizem a separação e a interdependência dos poderes, através da limitação do poder de desaplicação das leis com fundamento de inconstitucionalidade ou, em alternativa, da transposição do artigo 3. ․ do Código do Processo nos Tribunais Administrativos, tendo em vista regular a contenção dos juízes, no respeito devido aos outros poderes estaduais, seja perante a legitimidade política do parlamento e do governo, seja perante a legitimidade técnica da administração.

Em segundo lugar, foram apresentadas propostas tendentes a densificar o estatuto jurídico e deontológico dos juízes, sublinhando o perfil de titulares de órgãos de soberania, bem como de alteração dos mecanismos de nomeação e de promoção dos magistrados, visando uma maior abertura e responsabilização.

Em terceiro lugar, propostas de alteração da composição e funcionamento dos conselhos superiores, visando garantir um equilíbrio entre a representação corporativa e a legitimidade democrática, passando também pela integração do Conselho Superior dos Tribunais Administrativos e Fiscais no Conselho Superior de Magistratura. 
O período entre 2011 e 2015, no contexto de aplicação do Memorando de Entendimento assinado pelo governo e a troika e de execução do programa de ajustamento orçamental, foi muitas vezes, por iniciativa de deputados e do presidente da República, solicitada a fiscalização de constitucionalidade de várias medidas de política, designadamente as que implicavam cortes nas pensões e nos salários dos funcionários públicos. Os pareceres e acórdãos do Tribunal Constitucional relativos à constitucionalidade de tais medidas foram geradores de um debate sobre os seus poderes e competências e sobre a forma como estes eram exercidos. ${ }^{3}$ No debate público tornou-se evidente que os anos de aplicação do programa de ajustamento financeiro sob tutela da troika tiveram, para muitos portugueses, o efeito de revelar a Constituição. Funcionaram como uma espécie de raio $X$, mostrando uma parte do interior do corpo, que se sabe que existe, mas que não se sente. Se, por um lado, se fez sentir internamente a pressão externa (por parte dos mercados, das instituições da UE e da troika), e interna (por parte do governo de coligação PSD/CDS) para a perda de soberania, por outro, tomou-se consciência da importância das salvaguardas constitucionais na defesa dessa mesma soberania. ${ }^{4}$

\section{Notas finais}

Os artigos da Constituição em que se fundamentam as políticas públicas mantiveram-se ao longo dos últimos 30 anos praticamente inalterados. Nos debates sobre a revisão da Constituição promovidos em diferentes espaços, apenas os princípios relacionados com as políticas de justiça e o poder judicial têm suscitado controvérsia e propostas concretas de revisão. Mesmo no debate público suscitado pelos sucessivos pedidos de fiscalização de constitucionalidade das medidas de austeridade, que implicavam os cortes de salários e de pensões, nunca estiveram em causa os fundamentos constitucionais das políticas sociais. É necessário compreender se tal resulta do apoio unânime das forças partidárias a tais preceitos constitucionais ou se, pelo contrário, permanecem significativas diferenças político-partidárias que apenas se não manifestam por a relação de forças ser desfavorável a compromissos alternativos.

Em 1976, haviam passado apenas dois anos da Revolução de 25 de Abril e o texto constitucional foi o compromisso possível entre os principais partidos políticos. Já nessa altura, em muitos aspetos se registavam diferenças ideológicas e divergências de visão sobre os problemas do país e sobre os modelos de organização política e económica. Por exemplo, registavam-se divergências em torno do objetivo de "abertura do caminho para uma sociedade socialista", tendo em vista "a construção de uma sociedade sem classes", ou de "nacionalização dos principais meios de produção", ou

3 J. R. Novais, Em Defesa do Tribunal Constitucional, Coimbra, Edições Almedina, 2014; e G. A. Ribeiro et al., O Tribunal Constitucional e a Crise, Coimbra, Edições Almedina, 2014.

4 A aplicação do Memorando de Entendimento e das medidas de austeridade teve sobretudo efeitos devastadores pela degradação das condições materiais de vida e pelas ruturas nos quadros normativos vigentes, pela imprevisibilidde das novas regras e consequente quebra nas instituições e fragilização das organizações. Ver M. L. Rodrigues, e P. A. Silva, Governar com a Troika. Políticas Públicas em Tempo de Austeridade, Coimbra, Edições Almedina, 2015. 
ainda de manutenção dos militares no exercício do poder político, através do Conselho da Revolução. Contudo, apesar das diferenças entre os partidos políticos não terem sido anuladas, elas também não foram impeditivas da aprovação do texto constitucional, nem um obstáculo à construção de compromissos políticos duradouros. No mesmo sentido, os limites constitucionais - obrigações ou impedimentos colocados à ação governativa não foram impeditivos da alternância política, nem do pluralismo de visões e de orientações na ação governativa, que tornaram possível o desenvolvimento do estado social de direito e democrático. À Constituição e às leis de base setoriais estruturantes reconhece-se o mérito de se terem constituído como guias de ação, mas também como guias de não ação. Isto é, impediram que a alternância política esse traduzisse em ruturas institucionais, permitindo ainda assim a expressão de diversidade nas políticas públicas.

Apesar de estar prevista a possibilidade de fiscalização da inconstitucionalidade por omissão (artigo 283. ${ }^{\circ}$ ), sempre que os direitos, liberdades e garantias pressupõem a prestação pelo estado de serviços públicos, não há, na prática, mecanismos judiciais para exigir que o estado cumpra as obrigações constitucionais de promoção das políticas públicas sociais, visando a igualdade de oportunidades. A efetivação daqueles direitos não é algo que possa ser exigido individualmente pelos cidadãos através dos tribunais. A efetiva promoção de políticas públicas só pode ser assegurada por via política, pelas escolhas dos eleitores ou pelo não voto. Pode dizer-se que a garantia da igualdade de oportunidades e da concretização das políticas públicas depende da política e não do direito. Porém, sem a consagração das obrigações do estado no texto constitucional dificilmente teriam sido desenvolvidas as políticas públicas que levaram à construção do estado social e de direito que hoje temos.

Finalmente, embora o texto constitucional tenha sido decisivo para a concretização de políticas sociais e para a promoção da igualdade de oportunidades, Portugal continua a ser, na União Europeia, um dos países com mais elevados níveis de desigualdade. Para enfrentar o futuro com confiança vale pois a pena aprofundar o debate sobre a Constituição e as políticas públicas, procurando novos compromissos que permitam continuar a construir um país mais moderno, mais justo, mais igualitário.

Maria de Lurdes Rodrigues. Docente no Instituto Universitário de Lisboa (ISCTE-IUL) e coordenadora do Fórum das Políticas Públicas, Centro de Investigação e Estudos de Sociologia (CIES-IUL), Av. das Forças Armadas, 1649-026 Lisboa, Portugal. E-mail: mlurdes.rodrigues@iscte.pt

Pedro Adão e Silva. Docente no Instituto Universitário de Lisboa (ISCTE-IUL) e coordenador do Fórum das Políticas Públicas, Centro de Investigação e Estudos de Sociologia (CIES-IUL), Av. das Forças Armadas, 1649-026 Lisboa, Portugal. E-mail: padaoesilva@gmail.com 